\title{
Cystine Fluxes Across the Isolated Jejunal Epithelium in Cystinuria: Increased Efflux Permeability at the Luminal Membrane
}

\author{
J. F. DESJEUX, M. VONLANTHEN, A. M. DUMONTIER, O. SIMELL, AND M. LEGRAIN \\ INSERM U 290, Paris, France; Children's Hospital, University of Helsinki, Helsinki Finland; and Service de \\ Néphrologie, Hôpital de la Pitié, Paris, France
}

\begin{abstract}
In cystinuria, renal clearance of cystine frequently exceeds creatinine clearance, suggesting net cystine secretion; and absorption of the (di)basic amino acid is impaired at the luminal membrane of the jejunal and probably also renal tubular epithelium. We studied cystine transport in vitro in jejunal biopsy specimens of eight subjects with homozygous cystinuria and in 12 controls. Cellular/medium cystine distribution ratio was reduced in cystinuria $(1.36 \pm 0.36$ versus $5.36 \pm 0.61, p<0.001)$. Cystine influx across the luminal membrane was normal $\left(221 \pm 48\right.$ versus $\left.261 \pm 79 \mathrm{pmol} \cdot \mathrm{h}^{-1} \mathrm{~cm}^{-2}\right)$. Measurement of transepithelial cystine fluxes showed net absorption in controls but secretion in cystinuria. Apparent permeability coefficients were close to normal in cystinuria except that the efflux permeability at the luminal membrane was significantly increased $\left(0.839 \pm 0.22\right.$ versus $0.186 \pm 0.12 \cdot h^{-1}$ $\mathrm{cm}^{-2}$ ), and, accordingly, at the luminal membrane, the influx over efflux permeability ratio was small (1.01 \pm 0.50 versus $4.95 \pm 0.80, p<0.001$ ). The defect in cystine transport in cystinuria is apparently not caused by decreased influx but increased efflux of cystine (or cysteine) from the cell to the lumen across the luminal membrane. (Pediatr Res 21: 477-481, 1987)
\end{abstract}

$\quad$ Abbreviations
J, flux of cystine across a membrane
m, mucosal or luminal compartment
c, cellular compartment
s, "serosal" or blood compartment
Jmc, flux of cystine from mucosal to cell compartment
P, permeability
PEG, polyethylene glycol
PD, potential difference
Isc, short-circuit current
GFR, glomerular filtration rate

Cystinuria is characterized by increased urinary excretion of cystine and the basic amino acids lysine, arginine, and ornithine and by a tendency to form renal cystine stones (1-3). The amino acid transport defect, present in the mucosa of renal tubuli and small intestine, has been explained either by defective absorption or increased secretion of the amino acids or both $(2,4-9)$.

Amino acids and sodium are cotransported through the luminal membrane of the epithelial cells in proximal tubule and jejunum leading to intracellular accumulation of the amino acids

Received November 22, 1985; accepted December 10, 1986

Correspondence Dr. J. F. Desjeux, Inserm U 290, 107, Rue du Fg Saint-Denis, 75010 Paris, France. against a concentration gradient. At the basolateral membrane, amino acids leave the cell by facilitated diffusion (10). As a result amino acids are transported from lumen to blood in the absence of or against a concentration gradient. The relationship between $\mathrm{Na}^{+}$and amino acids is dependent on the nature of the amino acids and of the cells studied. In most cell types studied, basic amino acids are transported largely by system $\mathrm{y}^{+}$. This system is $\mathrm{Na}^{+}$independent but in renal and intestinal brush border membranes basic amino acid transport is partially $\mathrm{Na}^{+}$dependent (11). In the kidney, cystine transport is completely dependent on sodium, oxygen, and $\mathrm{pH}(12)$. The role of the luminal membrane in amino acid absorption can be examined experimentally by determination of the apparent amino acid permeabilities. Simply stated, an influx permeability greater than the efflux indicates an asymetry within the luminal membrane related to the active absorption of the amino acid considered.

In cystinuria, increased urinary excretion and intestinal malabsorption of the basic amino acids result from impaired $\mathrm{Na}^{+}$dependent influx at the luminal membrane (13). Intracellular accumulation of basic amino acids and cystine is decreased or absent in renal and jejunal epithelial cells in vitro, suggesting that the genetic transport defect is common for the basic amino acids $(6,8,13,15)$. However, the defect in cystine transport may differ from that in basic amino acid transport. The fact that cystine clearance frequently exceeds creatinine clearance $(4,7)$, even in the absence of cystine stones or cystine crystalluria, implies that cystine secretion (outward flux) may be important. Furthermore, occasional patients excrete only cystine (without basic amino acids) or basic amino acids without cystine $(16,18)$. This genetic heterogeneity suggests that cystine and basic amino acids may both have their own specific transport mechanisms in the kidney. In addition, cystine and cysteine are transported by two different mechanisms and the intracellular form of the amino acid is not the disulfide but the free thiol, cysteine. Based on these findings, existence of a luminal uptake defect common to all these four amino acids has been questioned.

In summary, a minimum of four different transport systems has been postulated: 1) a common system for cystine, lysine, arginine, and ornithine, 2) a common system for lysine, arginine, and ornithine, 3) a system specific for cystine, and 4) a system for cysteine. In addition, amino acid can be absorbed across the luminal membrane in the form of dipeptides, hydrolyzed in the cell, and transported by the transport system 2 , defective in lysinuric protein intolerance. It has also been suggested that the epithelial transport defect may differ in the kidney and intestine $(19,21)$, and that in the intestine the common process 1 is defective in cystinuria (21).

The object of this study was to locate the defect in cystine transport in cystinuria more precisely by measuring intracellular accumulation and transcellular fluxes of cystine in jejunal epithelium of cystinuric patients. The methods used have been 
effective in localizing the site of lysine transport defects to the luminal membrane in cystinuria and the basolateral membrane in lysinuric protein membranes (22). The results confirm decreased intracellular accumulation of cystine observed previously in vitro, and indicate that this diminished accumulation is caused by increased luminal efflux permeability at the brush border membrane.

\section{MATERIALS AND METHODS}

Patients. Eight cystinuric adults were studied, four from Finland and four from France. All had had cystine stones and had characteristic urinary aminoacidograms. D-Penicillamine treatment was stopped 3 days prior to intestinal biopsies. After informed consent, a jejunal biopsy was taken near the ligament of Treitz using a Carey capsule (23) positioned under fluoroscopic control. Two biopsies were obtained from each patient. The control group consisted of 12 subjects with normal urinary amino acids who were biopsied for other clinical reasons, or during a gastrointestinal resection. Biopsy samples were immediately placed in cold Ringer solution and studied within $1 \mathrm{hr}$.

Reagents. L-Cystine was purchased from Sigma Chemical Co., St. Louis, MO, $\mathrm{L}^{35} \mathrm{~S}$ cystine from Amersham, Buckinghamshire, England, $\mathrm{L}-3,3^{\prime 3}-\mathrm{H}$ cystine, ${ }^{22} \mathrm{Na}$ from Commissariat à l'Energie Atomique, Gif-sur-Yvette, France, and ${ }^{3} \mathrm{H}$ polyethylene glycol (4000 mol. wt.) from NEN, DuPont de Nemours, Paris, France.

In vitro studies. Intracellular $\mathrm{Na}^{+}$and Cystine Concentrations. These concentrations were measured as previously described using pieces of jejunal epithelium and the immediately underlying tissue without the muscular layer (22). In brief, the tissue was shaken at $37^{\circ} \mathrm{C}$ for $60 \mathrm{~min}$ in $10 \mathrm{ml}$ of Ringer containing 0.3 $\mathrm{mM}$ of $\mathrm{L}$-cystine, $1.5 \mu \mathrm{Ci}$ of $\mathrm{L}^{-35} \mathrm{~S}$ cystine, $1 \mu \mathrm{Ci}$ of ${ }^{22} \mathrm{Na}$, and $12.5 \mu \mathrm{Ci}$ of ${ }^{3} \mathrm{H}$ polyethylene glycol as an extracellular marker. The Ringer solution contained, in $\mathrm{mM}, 140 \mathrm{Na}, 5.2 \mathrm{~K}, 1.2 \mathrm{Ca}$, $1.2 \mathrm{Mg}, 120 \mathrm{Cl}, 25 \mathrm{HCO}_{3}, 2.4 \mathrm{HPO}_{4}$, and $0.4 \mathrm{H}_{2} \mathrm{PO}_{4}(\mathrm{pH} 7.4)$. After incubation the tissue was washed in cold $0.3 \mathrm{M}$ mannitol, blotted gently, weighed, and extracted in $2 \mathrm{ml}$ of $0.1 \mathrm{~N}$ nitric acid. Aliquots of the eluate were measured by liquid scintillation photometry. Results are given as the ratio of cellular to medium $(\mathrm{c} / \mathrm{m})$ cystine or $\mathrm{Na}$ concentration.

Cystine Influx. Cystine influx from the incubation medium across the luminal membrane into the cell $(\mathrm{Jmc})$ was determined as previously described (13). After $30 \mathrm{~min}$ preincubation in cystine-free Ringer solution, cystine influx, accurately timed at $60 \mathrm{~s}$, was measured in the presence of $0.3 \mathrm{mM}$ cystine and 1.5 $\mu \mathrm{Ci}$ of ${ }^{35} \mathrm{~S}$ cystine. The extracellular space was estimated with ${ }^{3} \mathrm{H}$ polyethylene glycol.

Transepithelial Fluxes. The biopsy specimen was mounted between two lucite chambers as a flat sheet on filter paper (13). The exposed area was $12.57 \mathrm{~mm}^{2}$. The tissue was bathed on both sides with identical Ringer solutions $(1.5 \mathrm{ml})$, which were circulated, oxygenated, and maintained at $37^{\circ} \mathrm{C}$. The solutions were connected via agar bridges to calomel electrodes for measurement of the transepithelial PD after appropriate correction for fluid resistance between PD-sensing bridges and for passing current through the system. Isc was expressed as $\mu \mathrm{Eq} / \mathrm{h}$ per $\mathrm{cm}^{2}$ to make it comparable with the cystine fluxes. After 5 min of steady Isc, $0.3 \mathrm{mM}$ cystine was added on both sides of the tissue and $5 \mu \mathrm{Ci}$ of $\mathrm{L}-3,3^{\prime}{ }^{3} \mathrm{H}$ cystine hydrochloride on the mucosal side. When the ${ }^{3} \mathrm{H}$ appeared in the opposite serosal chamber at a steady rate (within $5 \mathrm{~min}$ ), the flux from mucosa to serosa (Jms) was determined by collecting 200- $\mu$ l samples from the serosal reservoir at 5-min intervals and replacing them by the same amount of "cold" Ringer-cystine solution. After five flux periods, the bathing solutions were removed, and the chambers were washed and filled with cold Ringer plus $0.3 \mathrm{mM}$ cystine. Five $\mu \mathrm{Ci}$ of ${ }^{35} \mathrm{~S}$ cystine was added on the serosal side to allow similar determination of the flux from serosa to mucosa $(\mathrm{J} \mathrm{sm})$ for five periods.

Calculations. Fluxes $(\mathrm{J})$ between mucosal bathing solution $(\mathrm{m})$, cell compartment (c) and serosal bathing solution (s) were calculated as follows (22):

$$
\begin{gathered}
\mathrm{Jnet}=\mathrm{Jms}-\mathrm{Jsm}=\mathrm{Jmc}-\mathrm{Jcm}=\mathrm{Jcs}-\mathrm{Jsc} \\
\mathrm{Jms}=(\mathrm{Jmc} \times \mathrm{Jcs}) /(\mathrm{Jcm}+\mathrm{Jcs}) \\
\mathrm{Jsm}=(\mathrm{Jsc} \times \mathrm{Jcm}) /(\mathrm{Jcm}+\mathrm{Jcs}) \\
\mathrm{Jcm}=\mathrm{Jmc}-\mathrm{Jnet} \\
\mathrm{Jcs}=\mathrm{Jcm} /(\mathrm{Jmc} / \mathrm{Jms})-1 \\
\mathrm{Jsc}=\mathrm{Jcs}-\mathrm{Jnet}
\end{gathered}
$$

Intracellular $\mathrm{Na}^{+}$and cystine concentrations, transepithelial fluxes Jms and Jsm, and influx at the luminal membrane (Jmc) were obtained experimentally. The basic assumptions of the calculations (22) are: 1) The system is in a steady state as indicated by constant isotopic and electrical fluxes, 2) cystine is transported through one cellular compartment, i.e. the epithelial cells, 3) intracellular cystine to cysteine metabolism does not occur (see "Discussion"); the results are therefore expressed in ${ }^{35} \mathrm{~S}$ or ${ }^{3} \mathrm{H}$ "cystine-equivalents," and 4) the absence of a transconcentration effect across the luminal membrane. This point will be difficult to assess experimentally in cystinuria where the intracellular concentration remains low.

Each unidirectional flux is the product of the effective (or apparent) membrane permeability coefficient $(P)$ times the local concentration of cystine. Thus,

$$
\mathrm{Pmc}=\mathrm{Jmc} /[\text { cystine }] \mathrm{m}
$$

where [cystine]m is the cystine concentration in the mucosal solution. Similarly,

$$
\mathrm{Pcm}=\mathrm{Jcm} /[\text { cystine }] \mathrm{c}
$$

Determination of $\mathrm{P}$ is useful in characterization of the role of the membrane in cystine transport. A $\mathrm{Pmc} / \mathrm{Pcm}$ ratio greater than unity implies that uptake of cystine at the mucosal membrane occurs via facilitated transfer mechanism or active transport.

Statistics. Means $\pm \mathrm{SE}$ are reported with the number of determinations (n). Student's $t$ test for unpaired values and nonparametric tests (Mann-Whitney $U$ test and Wilcoxon onesample test) were used to compare means and ranges.

\section{RESULTS}

Intracellular cystine and sodium concentrations. The mean cellular to medium cystine ratio $( \pm \mathrm{SE})$ was $5.36 \pm 0.61$ in the controls, but was reduced in the cystinuric patients $(1.36 \pm 0.36)$ (Fig. 1). It differed significantly from that of the controls ( $p$ for difference $<0.001$ ). However, the patients' value did not differ significantly from unity. This absence of concentrating power in epithelial cells of cystinuric patients is in agreement with previous observations $(8,15)$. The sodium $\mathrm{c} / \mathrm{m}$ ratios were not statistically different in control and cystinuric tissues $(0.38 \pm 0.19$ and 0.30 \pm 0.11 , respectively)

Cystine influx. In principle, the difference in cystine or cysteine concentration within the cell may alter Jmc by a transconcentration effect (Fig. 2). The Jmc were therefore measured after a 30 min preincubation in cystine-free solution. Cystine influx at the luminal membrane was $261 \pm 79 \mathrm{nmol} \cdot \mathrm{h}^{-1} \cdot \mathrm{cm}^{-2}$ in the control group. Surprisingly, this flux was almost identical in cystinurics $\left(221 \pm 48 \mathrm{nmol} \cdot \mathrm{h}^{-1} \cdot \mathrm{cm}^{-2}\right)$.

Measured transepithelial cystine fluxes. In the five control samples studied, Jms was higher than Jsm, resulting in net cystine absorption in the absence of a transepithelial concentration gradient (Fig. 3). This net absorption was not statistically different from zero. In the epithelium of six cystinuric patients, Jms was diminished and Jsm was increased (but neither one significantly), leading to net cystine secretion. The two groups had 


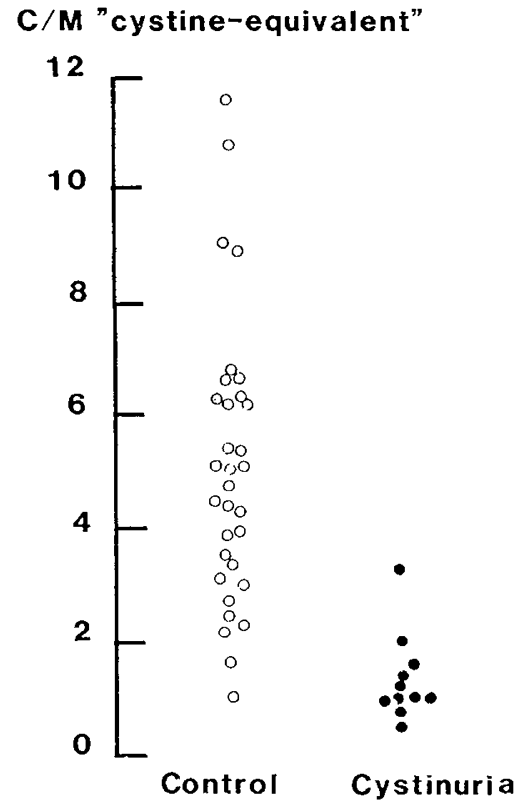

Fig. 1. Intracellular over medium ${ }^{35} \mathrm{~S}$ "cystine equivalent" ratio $(\mathrm{c} / \mathrm{m})$ in jejunal epithelial cells. Cystine concentration in medium was $0.3 \mathrm{mM}$. Thirty-two measurements in 10 controls; 11 determinations in six cystinuric patients.

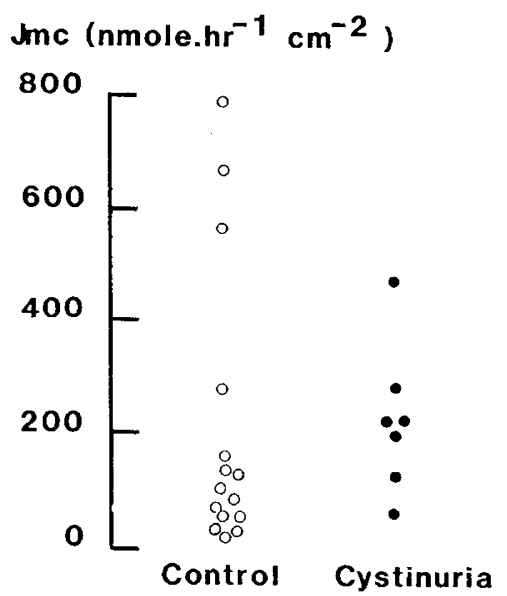

Fig. 2. Unidirectional cystine influx (Jmc) across the luminal membrane of jejunal epithelium. Fifteen measurements in eight controls; seven measurements in seven cystinuric patients.

similar electrical potential differences $(1.73 \pm 0.70$ versus $1.82 \pm$ $0.03 \mathrm{mV})$, Isc $\left(1.25 \pm 0.35\right.$ versus $\left.1.50 \pm 0.04 \mu \mathrm{Eq} \cdot \mathrm{h}^{-1} \cdot \mathrm{cm}^{-2}\right)$, and conductances $\left(19.6 \pm 1.2\right.$ versus $\left.22.1 \pm 0.8 \mathrm{mS} \cdot \mathrm{cm}^{-2}\right)$. The electrical parameters were stable throughout the experiments in both control and cystinuric tissues (results not shown), indicating steady electrolyte transport. The effect of cystine on Isc was too small (if any) to be detected in both control and cystinuric tissues.

Calculated fluxes. The calculated fluxes through the luminal membrane were identical in the two groups of patients. At the basolateral membrane Jcs, cystinuria was $43 \%$ of that in controls whereas Jsc was $62 \%$ smaller in controls than in cystinurics. Both differences were apparently linked with differences in intracellular cystine concentrations.

Calculated apparent permeability coefficients. The brush border membrane of cystinuric patients differed strikingly from that of the controls (Table 1). Pmc was not different, but Pcm was markedly elevated in cystinuria resulting in large reduction in the Pmc/Pcm ratio ( $p<0.001$ ). In control epithelium, the Pmc was approximately 5-fold as compared with $\mathrm{Pcm}$, whereas in cystinuria the $\mathrm{Pmc} / \mathrm{Pcm}$ ratio did not differ from unity. At the
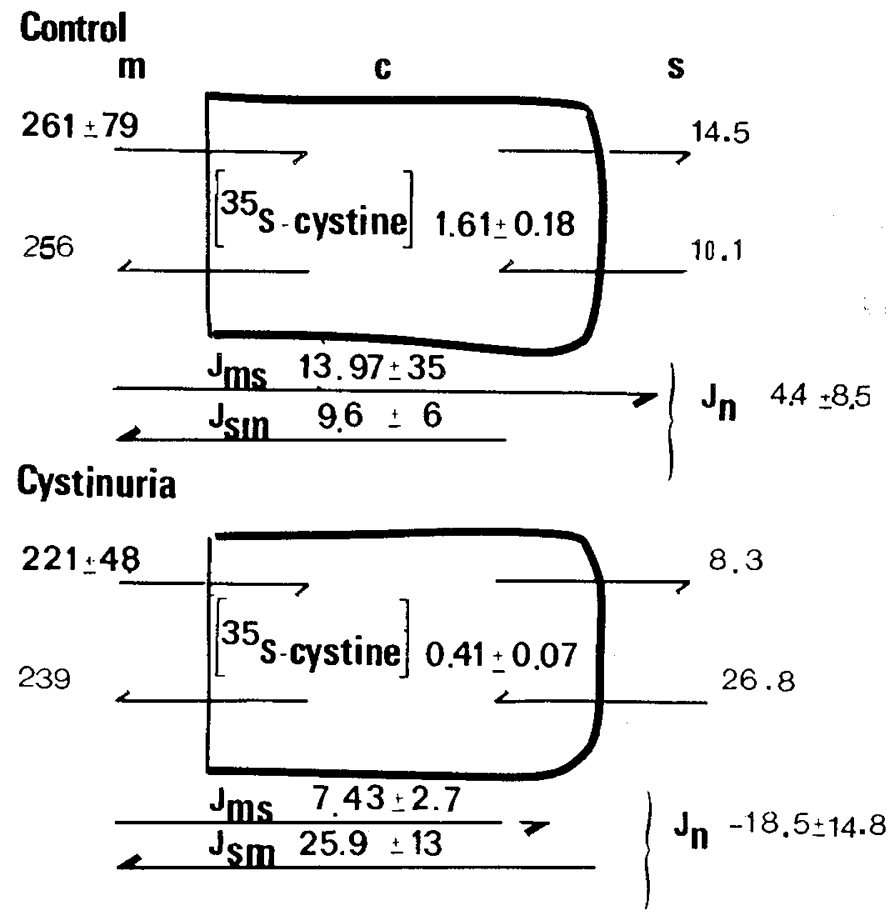

Fig. 3. Cystine fluxes (mean $\pm \mathrm{SE}$ ) across the epithelium of controls (upper panel) and cystinuric patients (lower panel). The transmural fluxes $\mathrm{Jms}$ and $\mathrm{Jsm}$, the unidirectional flux $\mathrm{Jmc}$, and the intracellular cystine concentration were obtained experimentally (bold face). The other fluxes $(\mathrm{Jcm}, \mathrm{Jcs}$, and $\mathrm{Jsc})$ were calculated from the measured mean values assuming that the tissue consists of a single compartment $(c)$ between mucosal $(m)$ and serosal $(s)$ solutions (light face). Fluxes are expressed in $\mathrm{nmol} \cdot \mathrm{h}^{-1} \mathrm{~cm}^{-2}$.

basolateral membrane, the apparent permeability coefficients did not differ statistically in the two groups and both had Psc/Pcs ratios greater than unity. Minor differences in the permeability values at the basolateral membrane are possible, but they are difficult to assess due to small actual values and large range of individual ratios.

\section{DISCUSSION}

Our results indicate that the altered cystine transport in cystinuria is not caused by reduced cystine entry at the luminal membrane of the enterocytes, but is rather related to increased cystine or cysteine efflux from the cell across the luminal membrane. This explanation is in particular based on the finding that cystine does not accumulate against a concentration gradient in cystinuric epithelium, even though the isotopic cystine influx across the luminal membrane is similar to that in normal epithelium. This loss of concentrative power, repeatedly found in both intestinal and renal cells $(8,15)$, is best explained by increased permeability of the luminal membrane to cystine or cysteine fluxes from the inside of the cell to the lumen.

This conclusion is in agreement with several tentative explanations of cystinuria (1, 3, 14, 20). In 1951, Dent and Rose (5) suggested that cystine, lysine, ornithine, and arginine were reabsorbed by a common renal tubular mechanism which was defective in cystinuria. This hypothesis is now well established for the three dibasic amino acids. However, genetic observations as well as in vivo and in vitro results exclude the possibility that cystine and dibasic amino acids are exclusively reabsorbed by a single common renal tubular system $(2,3)$. In the context of the present study, the most relevant observation is that in cystinuric patients, renal cystine clearance may exceed GFR, whereas dibasic amino acid clearances always are less than GFR. Although the precise mechanism of cystine secretion in the tubule has not been 
established, several authors have suggested cell-to-lumen secretion of cystine or cysteine combined with reduced entry across the luminal membrane $(1,8,24)$. Our results are consistent with secretion but not with reduced entry.

It is tempting to correlate our finding of increased cystine or cysteine efflux permeability with the finding of decreased lysine permeability (13). Schwartzman et al. (9) found that cysteine uptake by kidney cortex slices was stimulated when lysine was present in the medium because of the inhibition of the cystine efflux. Similar results were later obtained by Craan and Bergeron (20) who further demonstrated that this inhibition was competitive. Consequently, the secretion of "cystine-equivalents" observed in cystinuria might be due to decreased lysine influx permeability.

Our data are from jejunal epithelium. Direct permeability measurements in renal epithelial cells have so far not been possible in cystinuria. Thus, it is interesting to consider the renal validity of our data. Most genetic transport defects express themselves both in kidney and intestine. In 1961, Milne et al. (25) demonstrated that transport of basic amino acids is defective in both these organs in cystinuria. Results of studies using jejunal biopsy material in vitro correlate reasonably well with the in vivo results of proximal tubular function. This is the case of cystinuria, in which low lysine influx into enterocytes at the brush border membrane provided a cellular explanation for urinary lysine excretion (13). In lysinuric protein intolerance, the low lysine permeability at the basolateral enterocyte membrane similarly suggests a mechanism for increased urinary excretion of basic amino acids (22).

The similarity between kidney and intestine may be more qualitative than quantitative, as in congenital glucose and galactose malabsorption, where glucose transport is drastically reduced in the intestine but glucosuria is only intermittent (26). Further, in renal glucosuria, glucose is incompletely reabsorbed by the kidney tubules but is well absorbed by intestinal epithelial cells in vitro (27). In cystinuria, the discrepancy between the intestinal uptake in vitro and the pattern of urinary amino acid excretion in vivo is well documented and has been interpreted in terms of genetic heterogeneity $(15,21,28)$. It has been assumed that in jejunal epithelial cells, cystine is transported together with the three basic amino acids, and that the only genetic defect in cystinuria is the loss of a common transport system (8). Our results indicate that cystine influx is unchanged in cystinuria, whereas previous findings under the same experimental conditions showed that lysine influx was considerably diminished (13). Furthermore, our in vitro results fit well to cystine secretion observed in vivo. In conclusion, cystine transport is probably under the same genetic control in kidney and intestine.

Earlier studies suggest that cystine is reduced to cysteine after transport across the intestinal cell membrane (8). In the present experiments, fluxes were measured by means of isotopic tracers that do not distinguish between cystine and cysteine; they were therefore expressed in "cystine equivalents." The isotopic ${ }^{35} \mathrm{~S}$ influx Jmc was measured over a short period (60 s) usually considered brief enough to avoid significant amino acid metab- olism (29). Under these experimental conditions, Jmc of ${ }^{35} \mathrm{~S}$ probably represented cystine influx. Furthermore, the similitary of the results in controls and cystinuric patients strongly indicates that cystine influx across the brush border membrane is normal in cystinuria. This is the most important conclusion of our study that lead us to speculate that cystine efflux permeability is increased in cystinuria.

The efflux Jcm was calculated as the difference between $\mathrm{Jmc}$, measured for $60 \mathrm{~s}$ using ${ }^{35} \mathrm{~S}$ cystine, and Jnet, measured for 60 min using ${ }^{3} \mathrm{H}$ and ${ }^{35} \mathrm{~S}$ cystine as tracers. It is to note that the four major assumptions involved in the calculation must be explored in detail before a firm conclusion can be drawn. The exit permeability Pcm was calculated as the ratio of $\mathrm{Jcm}$ over the intracellular "cystine equivalents" concentration measured with ${ }^{35} \mathrm{~S}$ cystine over a 60 -min period. Under these experimental conditions, in which neither cystine nor cysteine was directly measured in the cellular water, it is difficult to assess the nature of the molecule that leaves the cell. In control tissues, cysteine is the most likely candidate (8). However, cystine may contribute to Jcm in cystinuria because no differences were found between controls and cystinuric subjects in intracellular concentrations when cysteine rather than cystine was used as the transported substrate (1). This result does not support an increased cysteine leak through the brush border membrane (1). On the other hand, in kidney cortex slices, the presence of lysine in the medium inhibited cysteine efflux but not that of cystine (9).

According to our results, in jejunal epithelial cells and possibly also renal tubular cells, net uptake at luminal membrane is impaired because cell to lumen flux is apparently elevated in cystinuria. The transepithelial absorption from lumen to blood is associated with functional and spatial asymmetry of the luminal and basolateral membranes in epithelial cells. In the simplest absorption model amino acid is pumped into the cell against a concentration gradient and leaves it downhill. The balance between the two processes determines the apparent concentrative power of the cell $(10,24,29)$. In the mucosal membrane of our control subjects, the uphill cystine transport was characterized by asymmetry of the apparent permeability coefficients (Pmc 5 times greater than Pcm). The relationship between the observed asymmetrical permeability and the previous finding of $\mathrm{Na}^{+}$and energy dependency of cystine transport in human intestinal cells (28) remains open. At the basolateral membrane, permeability was one order of magnitude lower than at the luminal membrane (Table 1), showing that cystine (or cysteine) can accumulate within the cell.

In cystinuria, the loss of asymmetrical permeability at the luminal membrane easily explains low intracellular cystine concentration and missing transepithelial absorption. Furthermore, the two conditions required for transepithelial secretion were fulfilled. First, Psc was present and second, $\mathrm{Pcm}$ was much greater than Pcs.

In conclusion, our results suggest diversity in the genetic control of basic amino acid and cystine transport in epithelial cells. In lysinuric protein intolerance, lysine efflux at the basolateral membrane is reduced (22). In cystinuria, lysine influx

Table 1. Calculated apparent permeability coefficients across the luminal and basolateral membranes in jejunal biopsies*

\begin{tabular}{lcccccc}
\hline & Pmc & Pcm & Pcs & Psc & Pmc/Pcm & Psc/Pcs \\
\hline Controls & $0.920 \pm 0.52$ & $0.186 \pm 0.12$ & $0.011 \pm 0.03$ & $0.017 \pm 0.02$ & $4.95 \pm 0.8$ & $1.55 \pm 2.9$ \\
& $(0.870)$ & $(0.159)$ & $(0.009)$ & $(0.033)$ & $(5.47)$ & $(3.66)$ \\
Cystinurics & $0.847 \pm 0.19$ & $0.839 \pm 0.22 \dagger$ & $0.027 \pm 0.01$ & $0.097 \pm 0.06$ & $1.01 \pm 0.5 \ddagger$ \\
& $(0.737)$ & $(0.583)$ & $(0.020)$ & $(0.089)$ & $3.59 \pm 2.3$ \\
& & & $(1.26)$ & $(4.45)$ \\
\hline
\end{tabular}

\footnotetext{
* Results are mean $\pm \mathrm{SE}$ (in $\mathrm{cm} \cdot \mathrm{h}^{-1}$ ) for four controls and five cystinuric patients. Each subject's data were obtained using the same piece of intestine. Figures shown in parentheses are calculated from the mean values in Figure 3, thus combining results obtained from different pieces of tissue.

$\dagger$ Significantly different from controls at $p<0.05$ level.

$\ddagger$ At $p<0.001$.
} 
permeability at the brush border membrane is markedly decreased (13), whereas cystine (or cysteine) influx permeability is not altered and efflux permeability at the same membrane is probably increased. The relationship between the two defects observed in cystinuria remains to be determined.

\section{REFERENCES}

1. Broadus AE, Thier SO 1979 Metabolic basis of renal-stone disease. N Engl J Med 300:839-845

2. Craan AG 1981 Cystinuria: the disease and its models. Life Sci $28: 5-22$

3. Scriver CR, Rosenberg LE 1973 Nature and disorders of cystine and dibasic amino acid transport. In: Scriver CR, Rosenberg LE (eds). Amino Acid Metabolism and its Disordrs, 1st ed. W.B. Saunders Company, Philadelphia, pp $155-186$

4. Crawhall JC, Segal S 1967 The intracellular ratio of cysteine and cystine in various tissues. Biochem J 105:891-896

5. Dent CE, Rose GA 1951 Amino acid metabolism in cystinuria. Q J Med 20:205-219

6. Fox M, Thier S, Rosenberg LE, Kiser W, Segal S 1964 Evidence against a single renal transport defect in cystinuria. N Engl J Med 270:556-561

7. Frimpter GW, Horwith M, Furth E, Fellows RE, Thompson DD 1962 Inulin and endogenous amino acid renal clearances in cystinuria: evidence for tubular secretion. J Clin Invest 41:281-288

8. Rosenberg LE, Crawhall JC, Segal S 1967 Intestinal transport of cystine and cysteine in man: evidence for separate mechanisms. J Clin Invest 46:30-34

9. Schwartzman L, Blair A, Segal S 1966 A common renal transport system for lysine, ornithine, arginine and cysteine. Biochem Biophys Res Commun 23:220-226

10. Munck BG 1981 Intestinal absorption of amino acids. In: Johnson LR (ed) Physiology of the Gastrointestinal Tract. Raven Press, New York, pp 10971122

11. White MF 1985 The transport of cationic amino acids across the plasma membrane of mammalian cells. Biochem Biophys Acta 822:355-374

12. Segal S, Crawhall JC 1968 Characteristics of cystine and cysteine transport in rat kidney cortex slices. Proc Natl Acad Sci USA 59:231-234

13. Coicadan L, Heyman M, Grasset E, Desjeux JF 1980 Cystinuria: reduced lysine permeability at the brush border of intestinal membrane cells. Pediatr
Res 14:109-112

14. Moatti N, Lemonnier A, Barthon F 1976 Effet de la cycloleucine sur la captation rénale des acides aminés dibasiques et de la cystine. Biomedicine 25:18-22

15. Morin CL, Thompson MW, Jackson SH, Sass-Kortsak A 1971 Biochemical and genetic studies in cystinuria: observations on double heterozygotes of genotype I/II. J Clin Invest 50:1961-1976

16. Brodehl J, Gellissen K, Kowalewsko S 1966 Isolated cystinuria (without lysineornithine-argininuria) in a family with hypocalcemic tetany. Proc Third Internatl Cong Neph, Washington, DC

17. Simell O, Perheentupa J, Rapola J, Visakorpi JK, Eskelin LE 1975 Lysinuric protein intolerance. Am J Med 59:229-240

18. Whelan DT, Scriver CR 1968 Hyperdibasic aminoaciduria: an inherited disorder of amino acid transport. Pediatr Res 2:525-534

19. Bannai S 1984 Transport of cystine and cysteine in mammalian cells. Biochim Biophys Acta 779:289-306

20. Craan AG, Bergeron M 1978 Experimental cystinuria: the cycloleucine model. II. Amino acid efflux from intestinal and renal tissues. Metabolism 27:16131625

21. Rosenberg LE 1967 Genetic heterogeneity in cystinuria. In: Nyhan WL (ed) Amino Acid Metabolism and Genetic Variation. McGraw-Hill Book Co, New York, pp 341-349

22. Desjeux JF, Rajantie J, Simell O, Dumontier AM, Perheentupa J 1980 Lysine fluxes across the jejunal epithelium in lysinuric protein intolerance. J Clin Invest 65:1382-1387

23. Carey JB 1964 A simplified gastrointestinal biopsy capsule. Gastroenterology 46:550-557

24. Schafer JA, Barfuss DW 1980 Membrane mechanisms for transepithelial amino acid absorption and secretion. Am J Physiol 238:F335-F346

25. Milne MD, Asatoor AM, Edwards KDG, Loughridge LW 1961 the intestinal absorption defect in cystinuria. Gut 2:323-337

26. Evans L, Grasset E, Heyman M, Dumontier AM, Beau JP, Desjeux JF 1985 Congenital selective malabsorption of glucose and galactose. J Pediatr Gastroenterol Nutr 4:878-886

27. Elsas LI, Rosenberg LE 1969 Familial renal glycosuria: a genetic reappraisal of hexose transport by kidney and intestine. J Clin Invest 48:1845-1854

28. Rosenberg LE, Downing S, Durant JL, Segal S 1966 Cystinuria: biochemical evidence for three genetically distinct diseases. J Clin Invest 45:365-371

29. Schultz SG, Curran PF 1970 Coupled transport of sodium and organic solutes. Physiol Rev 50:637-718 